\title{
Common origin of the 11307K APC polymorphism in Ashkenazi and non-Ashkenazi Jews
}

\author{
Yael Patael ${ }^{1}$, Arie Figer ${ }^{6}$, Ruth Gershoni-Baruch ${ }^{7}$, Moshe Z Papa $^{5}$, Shulamit Risel ${ }^{2}$, \\ Rakefet Shtoyerman-Chen ${ }^{4}$, Avraham Karasik ${ }^{3}$, Livia Theodor ${ }^{4}$ and Eitan Friedman ${ }^{1}$ \\ ${ }^{1}$ Susanne Levy Gertner Oncogenetics Unit, Institutes of ${ }^{2}$ Oncology, ${ }^{3}$ Endocrinology, and ${ }^{4}$ Gastroenterology \\ ${ }^{5}$ Department of Surgery, Chaim Sheba Medical Center, Tel-Hashomer \\ ${ }^{6}$ Institute of Oncology, Rabin Medical Center, Petah Tikvah \\ ${ }^{7}$ Genetics Institute, Rambam Medical Center, Haifa, Israel
}

\begin{abstract}
A common germline missense mutation within the $A P C$ gene, $I 1307 \mathrm{~K}$, has recently been described in Ashkenazi Jews. We detected this polymorphism in two non-Ashkenazi Jewish women using denaturing gradient gel electrophoresis (DGGE), and hypothesized that in Jewish individuals it might not be restricted to Ashkenazim, and actually reflect a common ancestral polymorphism. To test this notion we performed allelic pattern determination using APC-linked markers in these two women and in nine Ashkenazi carrier controls. The pattern of the intragenic markers, as well as a single downstream marker 30-70 Kb from the $A P C$ gene was identical in all individuals, regardless of ethnic origin. We conclude that the $11307 \mathrm{~K}$ polymorphism in Jewish individuals, is not restricted to Ashkenazim and probably reflects a founder mutation.
\end{abstract}

Keywords: Germline mutations; $A P C$ gene; founder effect; common haplotype; non-Ashkenazi Jews; DGGE

\section{Introduction}

Inactivating mutations within the $A P C$ gene have long been appreciated as underlying the rare familial cancer syndrome familial adenomatous polyposis (FAP) ${ }^{1-4}$ Recently, a novel missense mutation within the $A P C$ gene, I1307K, has been described in $28 \%$ of Jewish Ashkenazi individuals with familial colorectal cancer and, surprisingly, also in $6 \%$ of the general Jewish

Correspondence: Eitan Friedman MD, PhD, Chief, the Susanne Levy Gertner Oncogenetics Unit, Institute of Genetics, Chaim Sheba Medical Center, Tel-Hashomer, 52621, Israel. Tel: 9723530 3173; Fax: 9723535 7308; E-mail: feitan@post.tau.ac.il; or eitan 211@netvision.net.il

Received 17 July 1998; revised 4 January 1999; accepted 20 January 1999
Ashkenazi population. ${ }^{5}$ Mechanistically, this common polymorphism probably facilitates an acquired somatic inactivating mutation in $A P C$, an essential initial step in the development of the adenoma-carcinoma cascade of the colon. ${ }^{5,6}$ Thus far this specific polymorphism has been limited to Jews of east-European (Ashkenazi) extraction. Since we have detected the same mutation in two non-Ashkenazi individuals, one of Turkish and the other of Yemenite origin, we hypothesized that the I1307K polymorphism within the Jewish people may reflect a founder mutation and is not limited to Ashkenazim. Since the occurrence rate of this polymorphism in non-Jewish populations has not been systematically assessed, our observations and conclusions pertain only to Jewish individuals. 


\section{Materials and Methods}

\section{DNA Extraction}

DNA was extracted from peripheral blood leukocytes using standard techniques.

\section{PCRs for Allelic Pattern Determination}

Radioactive PCRs were performed in a final volume of $15 \mu \mathrm{l}$ and contained $32 \mathrm{P} \alpha \mathrm{dCTP}, 10$ picomole of each primer, standard $10 \times$ buffer $(2.5 \mathrm{mM} \mathrm{MgCl} 2)$, dNTPs and thermostable DNA polymerase (BioTaq, Appligene-Oncor, Watford, UK). Cycling was achieved in a thermocycler (PTC 100 60, MJ Research Inc., Watertown, MA, USA) using a standard cycling profile, with annealing at $50^{\circ} \mathrm{C}$. Following PCR, $5 \mu \mathrm{l}$ of the product mixed with gel loading buffer were electrophorosed on a $6 \%$ gel and autoradiographed for $24-72 \mathrm{~h}$. For non-radioactive PCRs, the final reaction volume was $50 \mu 1,30$ picomoles of each primer were used, and analysing PCR products was done on $1.5 \%$ agarose gels with ethidium bromide staining.

Six polymorphic loci from around the $A P C$ gene (5q15-q23) were used, three intragenic markers located at nucleotide positions $1458,5037^{7}$ and one located within exon 15 (position 5650). ${ }^{8}$ One marker (D5S346) is located $30-70 \mathrm{~Kb}$ downstream of the gene ${ }^{9}$ and two additional markers, D5S299 ${ }^{10}$ and D5S $82^{11}$ proximal to the $A P C$ gene.

Restriction enzyme digest used for allelic determinations was carried out as previously described ${ }^{7,8}$ with $25 \mu$ l of the PCR product digested with a large excess of enzyme for $4 \mathrm{~h}$, to the manufacturer's specified conditions. Digestion products were analysed after size separation on native polyacrylamide gel, as outlined for each specific marker. ${ }^{7,8}$

\section{Detection of the I1307K APC Polymorphism by Denaturing Gradient Gel Electrophoresis (DGGE)}

Melting Map Analysis The theoretical melting profile of the amplified fragment (from position 3902 to position 4304 of exon 15 of the $A P C$ gene) was generated using the Macmelt software, according to the algorithm of Lerman and co-workers. ${ }^{12}$

PCR These PCRs were done in a final reaction volume of $50 \mu$ l containing $0.5 \mathrm{U}$ thermostable DNA polymerase, $10 \times$ standard PCR buffer $(2.5 \mathrm{mM} \mathrm{MgCl}), 200 \mathrm{nM}$ of dNTPs, with 20 picomoles of each of the following primers:

Forward 5' - GC clamp-GGAAGCAGATTCTGCTAATACC-3';

\section{Reverse 5' - CCCTGCAGTCTGCTGGATTTGG-3'.}

Cycling was achieved in the same thermocycler as above, using a standard cycling profile with annealing at $56^{\circ} \mathrm{C}$ for 1 min. Following PCR, $10 \%$ of the product was analysed on a $1.5 \%$ agarose gel to ensure specificity and success of the reaction.

DGGE Parallel denaturing gradient gels with a denaturant range of $20-60 \%$ were cast and run using the D Gene apparatus (Bio-Rad, Richmond, CA, USA), according to the method of Myers and co-workers. ${ }^{13} 15-25 \mu l$ of the PCR reaction were loaded on to the gels, electrophorosed at $40 \mathrm{mAmp}$ (58C) for $16 \mathrm{~h}$, and stained with ethidium bromide.
Direct Sequencing DNA sequencing of the PCR products were formed after purification of the product by the Wizard Kit (Promega, Madison, WI, USA), and employing the Thermo Sequenase radiolabelled terminator cycle sequencing kit (Amersham Life Sciences, Piscataway, NJ, USA) according to the manufacturer's recommendations.

\section{Results}

\section{Patients' Characteristics}

All analysed patients had pathologically proven breast cancer, screened for being a carrier of the $11307 \mathrm{~K}$ APC polymorphism, as part of a larger, current study. ${ }^{14}$ Upon repeated questioning, there was no doubt as to the non-Ashkenazi origin of the two individuals, at least four generations back. As controls, we used DNA obtained from 43 Ashkenazi and 42 Yemenite individuals, not selected for any disease, who volunteered to donate blood as 'ethnic controls'. The ethnic origin of these individuals was ascertained at least three generations back. In addition, a single Ashkenazi family with a father who had colon cancer, and four of his daughters, two of whom had breast cancer, were also analysed.

\section{I1307K APC Mutation Carriers}

The presence of the $11307 \mathrm{~K}$ was heralded by an abnormal migration pattern on DGGE (Figure 1A). As is evident, this migration pattern abnormality is compatible with a heterozygous sequence alteration, as indeed, direct DNA sequencing of these individuals, showed the I1037K polymorphism in all samples (Figure 1B).

\section{Allelic Pattern Determination}

Allelic pattern analysis of six markers close to the $A P C$ gene, three being intragenic, is depicted in Figure $2 \mathrm{~A}$ and Figure 2B. All mutation carriers, Ashkenazi and non-Ashkenazi alike, shared a common allelic pattern in the three intragenic markers and the one $30-70 \mathrm{~Kb}$ downstream of it. Differences were detected between mutation carriers, even among Ashkenazi mutation carriers, with the more proximal markers, D5S82 and D5S299. In the family analysed (Figure 2C) both affected sisters who were $A P C$ I1307K carriers, shared an allele with the father, and the haplotype seen in these individuals was compatible with the 'common' four-allele pattern seen in all other mutation carriers. This 'common' four-marker haplotype was detected in 
A

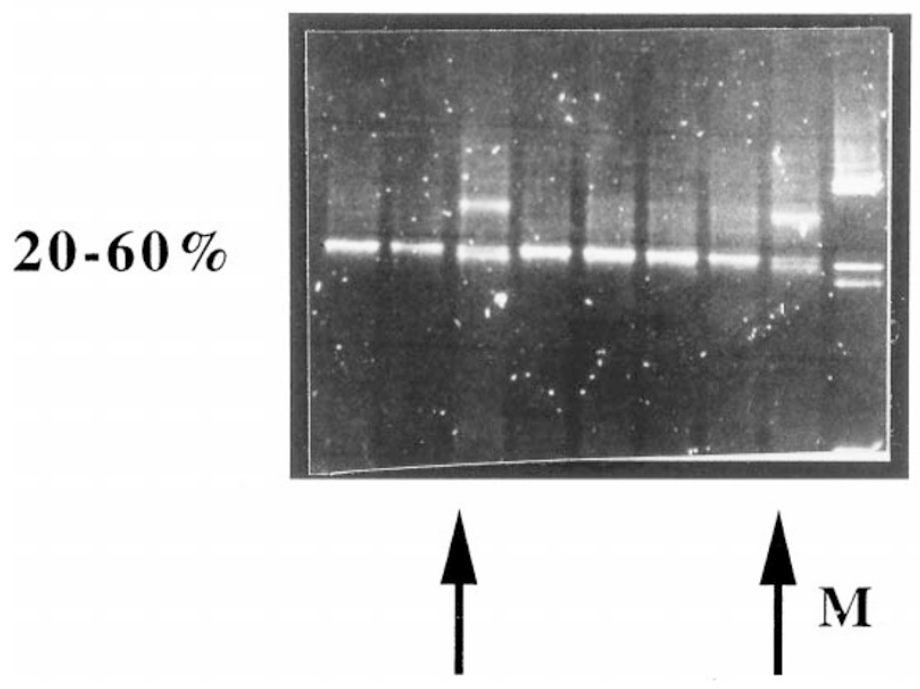

B

Figure 1 A DGGE analysis of the relevant fragment of the APC gene. Arrows below point to the abnormally migrating bands. M denotes size markers. The gel percentages are shown on the left. B Sequence showing the I1307K polymorphism. Wild type and mutant sequences are shown, and the polymorphism is indicated by an arrow.

18/43 (41\%) unselected Ashekenazi Jews and in 10/42 $(23.4 \%)$ unselected Yemenite Jews (data not shown).

\section{Discussion}

The $11307 \mathrm{~K} A P C$ polymorphism has been detected in two non-Ashkenazi individuals, and the allelic pattern of these mutation carriers was identical with that of nine Ashkenazi mutation carriers with intragenic APC markers and D5S346, the downstream marker. Furthermore, this 'common haplotype' was also shown to exist in a single Ashkenazi family. Several possibilities may account for this observation. First, the ethnic origin of the non-Ashkenazis was, in fact, Ashkenazi. This seems highly unlikely given the ascertainment of their pedigrees four generations back and to some extent their physical features. Furthermore, whilst there was a constant migration and mixing between the Jewish communities in Turkey and East Europe, the Yemenite population remained segregated with no real ties with the Ashkenazi population of East Europe. ${ }^{15,16}$ However, an Ashkenazi marrying into any of these two families earlier than can possibly be ascertained cannot be ruled out completely. Second, it might be that the polymorphism with this specific haplotype originated early in the history of the Jewish people, prior to the dispersion of the Yemenite Jews, circa 500 BC. ${ }^{15,16}$

Little has been published about the notion of a founder effect in $A P C$ mutation carriers. No founder mutations were detected in ethnically diverse codon 1309 AAAGA (3926del5) mutation carriers, ${ }^{17}$ including a single Israeli patient. In contrast, evidence for a common haplotype was reported in unrelated Portuguese families. ${ }^{18}$ Published analyses of unrelated, ethnically diverse Israeli APC families, did not elaborate on the possibility of a common founder. ${ }^{19}$ A divergence in the common haplotype was detected in Ashkenazi and non-Ashkenazi carriers using markers D5S82 and D5S299. This is not surprising given the distances of these markers from the APC gene itself, with recombination rates of $0.08-0.1 \%$, and an estimated physical distance of the D5S82 marker of more than $100 \mathrm{~Kb}$ from the gene itself. Thus, the region of $A P C$ that seems to be common to Ashkenazi and non-Ashkenazi mutation carriers, span the gene itself and at least $30 \mathrm{~Kb}$ telomeric to it.

We have also shown the ability of denaturing gradient gel electrophoresis (DGGE) to detect the I1307K polymorphism. Application of DGGE to this specific polymorphism is important, given the clustering of somatic mutations in the area immediately flanking codon 1307. ${ }^{5}$ Given the sensitivity and specificity of 
A
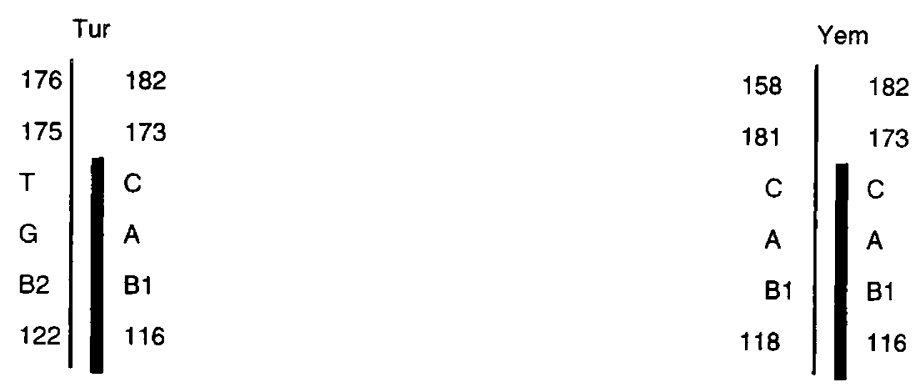

B
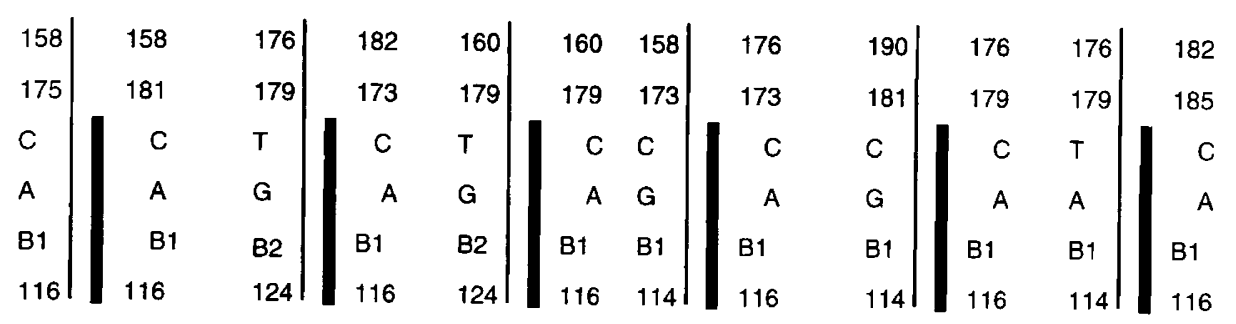

D5S299

D5S82

Nt 1458

$\mathrm{Nt} 5037$

Nt5650

C
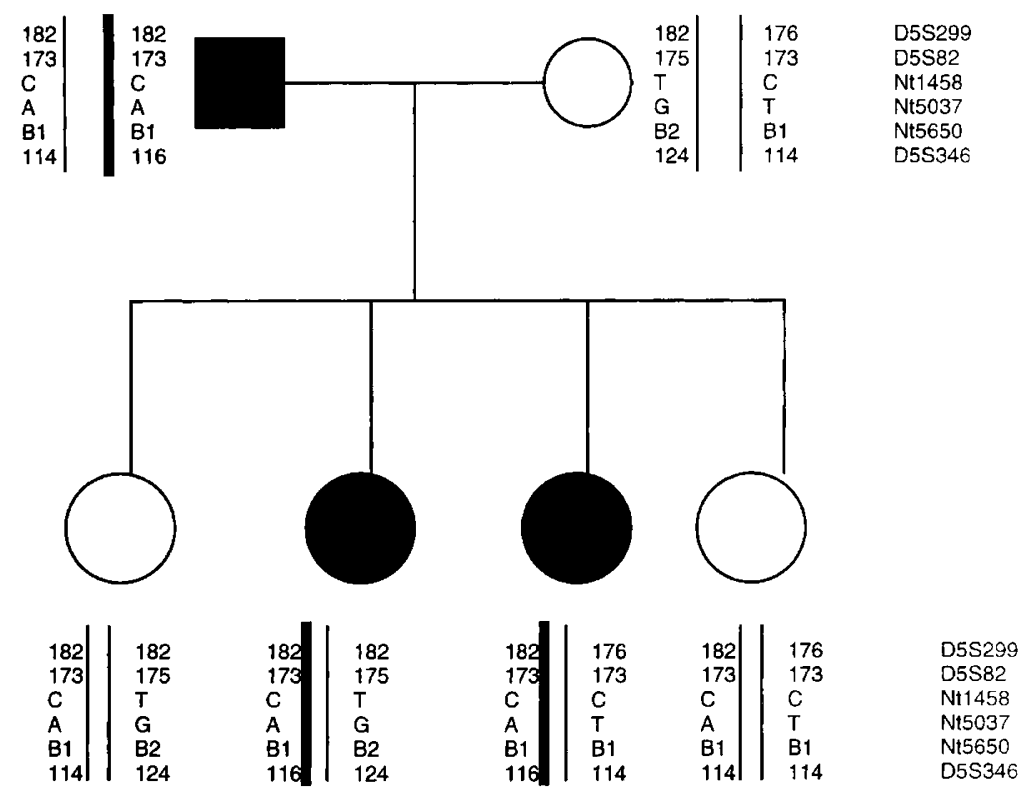

Figure 2 Allelic patterns of non-Ashkenazi I1307K APC mutation carriers (Yem = Yemenite; Tur = Turkish (A) and I1307K Ashkenazi I1307K APC mutation carriers (B) with APC linked markers. The marker order is given on the right, and the common allelic pattern is shown in bold. Panel $C$ depicts the haplotype in a single Ashkenazi family with three APC 1307K carriers. The two female carriers had breast cancer, and the father had colon cancer. The common haplotype is shown in bold.

DGGE and its proven value in this gene region, it should be considered as a first choice for mutational screen of this specific APC region.

From the clinical perspective, it seems that similar to the inherited susceptibility to breast and ovarian cancer in the Jewish people, the predominant sequence alteration in $A P C$ amongst Jewish people is not limited to the Ashkenazi population, and that genetic testing for this specific mutation should be offered to familial colorectal cancer Jewish individuals, regardless of ethnic 
origin. It should be re-emphasised that these conclusions should only be applied to Jewish individuals, as the rate of this specific polymorphism in non-Jewish populations, is still to be systematically evaluated.

\section{Acknowledgment}

This work was performed in partial fulfilment of the requirements for the $\mathrm{PhD}$ degree for Yael Patael from the Sackler School of Medicine at the Tel-Aviv University.

\section{References}

1 Groden J, Thliveris A, Samowitz WS et al: Identification and characterization of the familial adenomatous polyposis gene. Cell 1991; 66: 589-600.

2 Leppert M, Burt R, Hughes J et al: Genetic analysis of an inherited predisposition to colon cancer in a family with a variable number of adenomatous polyps. $N$ Engl $\mathrm{J} \mathrm{Med}$ 1990; 322: 904-908.

3 Burt RW, Samowits WS: The adenomatous polyp and the hereditary polyposis syndromes. Gastroenterol Clin North Am 1988; 17: 657-678.

4 Nishisho I, Nakamura Y, Miyoshi Y et al: Mutations of chromosome 5q21 genes in FAP in colorectal cancer patients. Science 1991; 253: 665-669.

5 Laken SJ, Petersen GM, Gruber SB et al: Familial colorectal cancer in Ashkenazim due to hypermutable tract in APC. Nat Genet 1997; 17: 79-83.

6 Kinzler KW, Vogelstein B: Lessons from hereditary colorectal cancer. Cell 1996; 87: 159-170.

7 Kraus C, Ballhausen WG: Two intragenic polymorphisms of the APC-gene detected by PCR and enzymatic digestion. Hum Genet 1992; 88: 705-706.

8 Cottrell S, Bodmer WF: Two Msp1 polymorphisms within the APC gene. Hum Mol Genet 1992; 1: 352.
9 Spirio L, Joslyn G, Nelson L, Leppert M, White R: A CA repeat $30-70 \mathrm{~KB}$ downstream from the adenomatous polyposis coli (APC) gene. Nucleic Acids Res 1991; 19: 6348.

10 van Leeuwen C, Tops C, Breukel C, van der Klift H, Fodde R, Khan PM: CA repeat polymorphism at the D5S299 locus linked to adenomatous polyposis coli (APC). Nucleic Acids Res 1991; 19: 5805.

11 Bruekel C, Tops C, van Leeuwen C et al: CA repeat polymorphism at the D5S82 locus proximal to adenomatous polyposis coli (APC). Nucleic Acids Res 1991; 19: 5804.

12 Lerman LS, Fischer SG, Hurley I, Silverstein K, Lumelsky N: Sequence-determined DNA separations. Ann Rev Biophys Bioeng 1984; 13: 399-423.

13 Myers RM, Maniatis T, Lerman LS: Detection and localization of single base changes by denaturing gradient gel electrophoresis. In: Wu, R (ed). Methods Enzymology, Academic Press: San Diego, 1987; 155: 501-527.

14 Gershori-Baruch R, Patael Y, Dagan E et al: The I1307K APC mutation and breast cancer risk: More questions than answers. Human Molec. Genetics, 1999 (submitted).

15 Goodman RM: A perspective of genetic diseases among the Jewish people. In: Goodman RM and Moutulsky AG (eds). Genetic Disorders among the Jewish People, Johns Hopkins University Press, Baltimore, 1979; 1-29.

16 Bonne-Tamir B, Zoosman-Disakin A, Ticher A: Genetic diversity among Jews re-examined preliminary analysis at the DNA level in Genetic diversity among Jews. In: Bonne-Tamir B and Adam A (eds). Diseases and Markers at the DNA level. Oxford University Press, New York, 1992, pp 80-94.

17 Delhanty JDA, Tsioupra K: Haplotype comparison in fresh mutation cases of adenomatous polyposis coli due to deletion AAAGA at codon 1309. Ann Hum Genet 1995; 59: 39-42.

18 Almeida R, Morton N, Fidalgo P et al: APC intragenic haplotypes in familial adenomatous polyposis. Clin Genet 1996; 50: 483-485.

19 Amikam D, Niv D, Lachter J, Eidelman S, Ben-Ishai Z: The use of DNA markers in the preclinical diagnosis of familial adenomatous polyposis. Isr J Med Sci 1997; 33: 8-13. 